\title{
(息)
}

Citation:

Foster, R and Fitzgerald, H and Stride, A (2019) The socialization and participation of Deaflympians in sport. Sport in Society, 22 (12). pp. 1904-1918. ISSN 1743-0437 DOI: https://doi.org/10.1080/17430437.2018.1530219

Link to Leeds Beckett Repository record:

https://eprints.leedsbeckett.ac.uk/id/eprint/5450/

Document Version:

Article (Accepted Version)

This is an Accepted Manuscript of an article published by Taylor \& Francis in Sport in Society on 04 November 2018, available online: http://www.tandfonline.com/10.1080/17430437.2018.1530219

The aim of the Leeds Beckett Repository is to provide open access to our research, as required by funder policies and permitted by publishers and copyright law.

The Leeds Beckett repository holds a wide range of publications, each of which has been checked for copyright and the relevant embargo period has been applied by the Research Services team.

We operate on a standard take-down policy. If you are the author or publisher of an output and you would like it removed from the repository, please contact us and we will investigate on a case-by-case basis.

Each thesis in the repository has been cleared where necessary by the author for third party copyright. If you would like a thesis to be removed from the repository or believe there is an issue with copyright, please contact us on openaccess@leedsbeckett.ac.uk and we will investigate on a case-by-case basis. 


\section{The socialization and participation of Deaflympians in sport}

\section{Rebecca Foster, Hayley Fitzgerald \& Annette Stride}

\section{Introduction}

The recent Paralympics in London and Rio offered a global platform for promoting a greater awareness of elite disability sport. In part, these events have also contributed to (re)considering understandings of disabled people more broadly within society. For example, research conducted after the 2012 Paralympics revealed that over $40 \%$ of disabled and nondisabled people had a more positive view of disabled people following the Paralympics (Department for Work and Pensions, 2014). Similarly, research undertaken just before Rio 2016 revealed that $78 \%$ of disabled people believe the Paralympics improve attitudes towards disabled people within society (SCOPE, 2016). Within the United Kingdom, Channel 4's coverage of the last two Paralympics, along with increased exposure in the media, has also been attributed as a key influence contributing to changing views of disability sport and disabled people. Whilst these are positive developments it should be recognized that this kind of coverage is largely limited to a relatively short time frame and there continues to be calls for long-term efforts to improve the amount and nature of media coverage in-between Paralympic years (Beacom, French and Kendall, 2016; Goggin and Hutchins, 2017).

It should be noted that the Paralympics represent only a partial insight into disability sport. Like other elite sporting events, the Paralympics explicitly operates within a performance domain and therefore does not account for those engaging in community (disability) sport within the participation domain. Indeed, even though the Paralympics represent people with diverse impairments is it worth noting that athletes with learning disabilities and profound and multiple disabilities have been marginalized (Jobling, Jobling and Fitzgerald, 2008). Therefore, when participation in sport is considered only within the elite domain, such as the 
Paralympics, it is limiting as it does not represent the diverse range of disabled people within society. Some have argued this kind of representation is counterproductive to disability rights (Braye, Dixon and Gibbons, 2013). Moreover, athletes who are D/deaf do not have a classification within the Paralympics, apart from if they have another disability that qualify them to compete in the Paralympics. As we discuss later, D/deaf people can compete in the Deaflympics. This is an elite sporting event open to those athletes with level of deafness medically defined as 55dB in their better ear (Harrison, 2014). The most recent Deaflympics took place in Turkey, in the summer of 2017, an event we suspect has gone largely unnoticed by many outside the $\mathrm{D} /$ deaf community.

Situated within this wider debate around recognition and representation within sport this paper focuses upon D/deaf athletes in order to offer some initial observations about this often ignored group of athletes. By discussing D/deaf athletes together with disabled people and the Paralympics we acknowledge this is not a straightforward relationship, something we explore later in the paper in relation to D/deaf identity. We also recognise the language used to talk about Deaf/deaf people is open to considerable debate. Indeed, similar impassioned discussions are evident in relation to understandings of disability (see for example: Barnes, Mercer and Shakespeare, 1999 and Kiuppis, 2016). In adopting the term 'D/deaf people' rather than 'people who are D/deaf', we have taken up Barnes et al. (1999: 7) thinking who point to the need to avoid the phrase 'people with ....'. They argue this "blurs the crucial conceptual distinction between impairment and disability and avoids the question of causality". We believe this perspective can also be applied to discussions about D/deaf people. Within this paper we also utilise Valentine and Skelton's (2003) notion of 'D/deaf'. Adopting this term recognizes those who associate 'Deafness' as a linguistic minority and also those who understand 'deafness' as an impairment measured against notions of 'normal' 
hearing. Therefore, by using the term D/deaf we seek to account for the different ways people identity with, and understand, D/deafness ${ }^{\mathrm{i}}$.

The key questions we address in this paper are: (1) What are the key factors enabling D/deaf athletes' involvement and progression in elite D/deaf sport? (2) What are the key challenges D/deaf athletes face when participating and progressing in D/deaf sport? In order to begin to explore these questions four in-depth interviews were conducted with athletes who competed in the 2013 Deaflympics. First we consider a number of key stages in athlete development and how these relate to D/deaf athletes. As part of this discussion we briefly outline how the Deaflympics are situated within wider sporting structures and practices. After this we explore D/deaf people as a linguistic minority and the idea of 'Deaf gain' and 'hearing loss'. We then present the findings from interviews with the Deaflympians in relation to four themes: 'sampling years and sports participation', 'discovering D/deaf sport', 'the status and value of D/deaf sport' and 'socially constructing 'hearing loss". In concluding we offer a number of observations about the findings and research about D/deaf sport. We hope this small-scale study offers some initial insights about the possibilities and challenges that emerge when enabling $\mathrm{D} / \mathrm{deaf}$ people to participate in sport.

\section{Athlete development, D/deaf Sport and the Deaflympics}

A number of models have been developed that outline various stages of athlete development. That is, the ways in which athletes are socialized into sport and sustain participation. The interest of long-term athlete development in sport has gained momentum in recent years as coaches, coach educators and governing bodies of sport seek to more effectively plan and support athlete development. In their review Lloyd, et al. (2015) discuss a of number of models that account for the different stages of athlete development including, the 
Differentiated Model of Giftedness and Talent (DMGT) (see: Gagne'1993), the Model of Talent Development in Physical Education (see: Bailey and Morley 2006) and the Developmental Model of Sports Participation (DMSP) (see: Côté and Hay, 2002). Each of these models emphasizes, in different ways, educational, elite sport and broader dimensions to development. The Developmental Model of Sports Participation reflects an educational and elite sport philosophy and in doing this accounts for engagement in multiple sports and then moving into specializing. More specifically, Côté, Baker and Abernethy (2007) and Côté and Hay (2002) distinguish between three distinct stages of development including the sampling years (6-12 years), the specializing years (13-15 years), and the investment years (16 years and over).

During the sampling years young people sample a range of sports and participation is premised on experiencing fun and enjoyment, what is described as 'deliberate play'. By engaging in deliberate play the foundations are established for young people to feel intrinsically motivated by sport (Côté, et al., 2007 and Côté and Faser-Thomas, 2007). Experiences of physical education, family interests in sport, and friendship networks have all been cited as facilitators of sport during this time (Wheeler and Green, 2014). Interestingly, data illustrates that during this sampling stage significantly fewer D/deaf or hearing impaired children take part in sport when compared with hearing children (Sport England, 2001). The transition between school and adult participation also offers challenges for disabled people and those who are D/deaf (National Disability Sport Organisations, 2015). Côté and Hay (2002) also outline specializing and elite development stages. The specializing years (13-15 years) typically involve one or two activities and the development of sport specific skills. Through this specialisation the focus of participation includes 'deliberate play' and also 'deliberate practice'. From this stage a young person may move to elite/performance level, 
participate regularly in recreational sport, or drop out. Again, during this stage fewer D/deaf youth take part in sport when compared to the hearing population (Sport England, 2017). During the investment years (16 years onwards) the nature of the pathway, either elite/performance or recreational will influence the balance between 'deliberate play' and 'deliberate practice'. Here those channelled towards elite/performance are likely to work with a specialist coach within a performance-orientated environment and the focus will be on high amounts of 'deliberate practice' (Côté and Faser-Thomas, 2007). Within this performanceorientated setting Clark and Mesch (2018) recently note D/deaf women are less likely to participate in the Deaflympics or hold leadership roles in sport when compared to their male counterparts.

There are important differences in addition to lower participation levels to note regarding the potential engagement of D/deaf people in sport. First, at any of these athlete development stages $\mathrm{D} /$ deaf people may be exposed to separate 'deaf sport' opportunities, that is, sporting activities specifically offered to D/deaf people. Indeed, it is often deaf schools or D/deaf family members who are the catalyst for socializing young people into D/deaf sport. During an athlete's career these D/deaf sport contexts may be the primary outlet supporting progression between sampling, specializing and investments years. Second, within a D/deaf sport setting the scope of possibilities for engaging competitively at the specialising and investment stages will be restricted to those D/deaf sports with clubs and competition structures supporting these opportunities. Therefore, the nature of these sporting opportunities may influence which specific sport(s) a D/deaf person is socialised into. Third, D/deaf people may simultaneously participate in sport through a combination of settings including mainstream, disability sport, and D/deaf sport opportunities. In this way, they crosscut various sports within diverse contexts (mainstream sport, disability sport, deaf sports clubs, 
competitions and teams) and at different levels of participation (recreational/performance). Whilst these opportunities may seem to offer greater possibilities for activity choice and inclusion based on the preference of a D/deaf person they also add complexity to the landscape of sport for D/deaf people. As a result those supporting D/deaf people to participate in sport may not be aware of these different opportunities and therefore may not direct potential participants into these different avenues of participation. Fourth, by cross-cutting these settings a D/deaf athlete may be positioned and understood differently in the same sport. For example, at the specializing stage (s)he could be training with a national Deaf sport squad and considered by the squad members and coaches as elite/performance orientated. In contrast, (s)he may also train, and compete, in a local mainstream club/league and in this setting may not be considered to be an elite performer.

The pattern of separate or mainstream sports provision mirrors the historic treatment of D/deaf people more generally within society. For example, legislation and policy has promoted separate education provision for D/deaf people (Atherton, 2009a). Whilst much of this separation has been imposed, D/deaf people themselves have also proactively sought separation. For example, there is a long tradition of Deaf clubs and these are recognized as an important setting in which a sense of community and normality are experienced by D/deaf people (Atherton, 2009b and 2012; Solvang and Haualand, 2014). Internationally, the Deaflympics has also developed specifically with D/deaf people in mind (Peers, 2018). The Deaflympics, previously known as the World Deaf Games, and the Silent Games, were established in 1924. Since these inaugural games, the Deaflympics have steadily grown in terms of participants and range of sports. Twenty sports feature within the Summer Deaflympics and five sports are included in the programme for the Winter Deaflympics. Participants of the Deaflympics are not allowed to compete using hearing aids or any other 
hearing devices. During competitions, referees and other officials use visual tools such as flashing lights, hand signals and flags to communicate decisions (Harrison, 2014; Clark and Mesch, 2018). If a D/deaf athlete is sufficiently talented they can, and have, competed in the Olympics. However, for a D/deaf athlete to compete in the Paralympics they must have an additional impairment (such as a physical disability) (Harrison, 2014). Like any form of classification, there may be those who do not this level of deafness but consider themselves to be deaf. But they would not qualify for the Deaflympics, as they are not classed as being sufficiently deaf. It could be argued that many D/deaf athletes are lost within the current elite sporting structures as they are neither deaf enough to take part in the Deaflympics, classified in ways recognized for the Paralympics, nor talented enough to reach the Olympic qualifying standard or selection.

By promoting separate provision through Deaf clubs and the Deaflympics a wider debate has emerged around how best to support different groups, including D/deaf people, to participate in sport. In relation to separate and integrated provision, Fitzgerald and Long (2017) pose a number of key questions including: Who is deemed to be in need of integration? How best do we integrate? And, what are the merits of supporting these different types of sporting opportunities? Discussions focusing on D/deaf people and sport are often compounded when D/deaf people are grouped with disabled people. Here it should be recognized that not all D/deaf people identify with being disabled and may be reluctant to use provision specifically for disabled people. This was particularly evident among some of the D/deaf participants in research undertaken by Rankin (2012). These participants would not attend sporting events for disabled people, as they did not consider themselves to be disabled, insisting that the only barrier to accessing integrated provision is accessible communication. For D/deaf people, Ammons and Eickman (2011) argue that they do not properly fit the category of either non- 
disabled or disabled and consequently their needs are overlooked when they are assigned to either category. Identity would seem to be an important constituent influencing the choices D/deaf people make about how, where and with whom they engage in sport. Next, consideration is given to $\mathrm{D} /$ deaf identity.

\section{Understanding D/deaf Identity}

As we have just outlined provision of sporting opportunities for $\mathrm{D} / \mathrm{deaf}$ people is not straightforward. More broadly, the notion of D/deaf identity is complex and different understandings have implications for how D/deaf people understand themselves and are understood by others within society (Atherton, 2009a; Dirksen, Bauman and Murray, 2014). We have found the thinking of Valentine and Skelton (2003) useful for better understanding D/deaf people within society and sport. For example, they use the term Deaf (upper case ' $D$ ') to recognize a linguistic minority and any association with disability is rejected. From this perspective there is a recognition that discrimination occurs because a hearing society excludes $\mathrm{D} /$ deaf people. That is society is not organized in a manner that is inclusive of D/deaf people and excludes by prioritising audio forms of communication. In contrast, the term deaf (lower case ' $d$ ') is used when individuals acknowledge having an impairment based upon medically defined notions of 'normal' hearing. As the Table 1 illustrates there are a number of ways to medically define hearing loss.

\section{INSERT TABLE 1 HERE}

This way of medically defining deaf people is often used when people have acquired hearing loss. Interestingly, Bauman and Murray (2010) term 'hearing loss' as the lack or loss of hearing that creates a disadvantage to the individual. They also recognize the possibilities of 
'Deaf gain', where the benefits of deafness are highlighted rather than ignored. To be D/deaf is not seen as negative or something that is devalued. For example, Bahan (2008) argues that with British Sign Language (BSL) being a visual language, D/deaf people often have an enhanced perception of facial recognition and well-developed peripheral vision. These qualities can be beneficial in sport and offer D/deaf athletes possibilities to remain focused in pressurized situations by not processing external auditory cues that may typically be distracting to hearing people. Similarly, the idea of 'feeling' sport rather than relying on auditory feedback (for example having an awareness that a competitor is in close proximity because you are aware of rhythmic breathing in the air and this can be felt on a particular part of your body) could be seen as advantageous. The concept of Deaf gain is part of a wider mobilization by $\mathrm{D} / \mathrm{deaf}$ communities to redefine in positive terms $\mathrm{D} / \mathrm{deaf}$ people, their culture and language (Dirksen, Bauman and Murray, 2014; Ladd and Lane 2013).

In distinguishing between different kinds of D/deaf identity is it also important to recognize that deafness may be part of a multi-faceted identity that encompasses gender, ethnicity, dis/ability, sexuality and social class. Valentine (2007) believes that different aspects of someone's identity can become more, or less, significant over particular periods of time, through different interactions, and across different social settings. The idea of space is particularly important in contributing to a person's sense of self; we move within and between spaces, meet other people and are exposed to different cultures and beliefs. As such, identity is never fixed but rather a 'situated accomplishment' (West and Fenstermaker, 1995). Valentine (2007) usefully captures the idea of situated accomplishments in a series of short stories about Jeanette. As this character moves between different spaces particular identity markers become more or less salient and position her 'in' and 'out' of place in particular spaces. For example, whilst Jeanette's D/deaf identity ensures her inclusion within a Deaf 
community club, her sexuality as a lesbian proves to be more problematic within this setting and for the people occupying it. Yet, her D/deaf identity marks her as different within the hearing culture at work. Within these different contexts it is clear that the idea of 'hearing loss' and 'Deaf gain' will be experienced in different ways by D/deaf people, like Jeanette, and also interpreted differently by others occupying these spaces. In order to begin to understand D/deaf athletes and their experiences of sport we next map out the methodology underpinning this research.

\section{Research Context}

The data reported in this paper were generated from four Deaflympians who have represented Great Britain. Each of these athletes were interviewed by the first author during the 2013 Deaflympics. This event is one of the only occasions when all British athletes are together. Initially, ten athletes agreed to be interviewed. However, the geographical spread of the athletes during the competition and the limited pockets of time available meant that only four interviews were possible. The interviews were completed after the athletes had competed and at a time convenient to them. Three of the athletes were oral, so no interpreter was needed. One athlete communicated using BSL, so with the athlete's permission, the team interpreter provided interpreting services for the interviewer and athlete. A brief overview of each of the athletes is provided in the table below.

\section{INSERT TABLE 2 HERE}

Each of the four interviews were recorded on an audiotape and then transcribed. The transcripts were coded into categories and key themes developed and sorted. Following the constant comparison method of analyzing data we continually reviewed and reworked these categories and themes. 
It should be noted that the first author was also one of the team managers for the Deaflympic athletics team during this competition. We recognize this position created a number of opportunities and challenges. Similar to the reflections of Macbeth (2010), the first author could be considered in terms of her 'insiderness'. For example, she was part of the athletics squad in her role as manager and was an ex-athlete and user of BSL. This background proved advantageous when negotiating access to the athletes and also enabled the first author to have a shared experience of the event and D/deaf sport more broadly with the athletes. This connectivity with the athletes also created ethical complications in terms of the dual role of manager and researcher. For instance, we recognize this opens up the possibilities of compromise particularly in relation to the researcher/manager power dynamics with the athletes. We tried to limit the likelihood of athletes feeling that they had to participate in the research by ensuring that any communications with them clearly delineated between the different roles of the first author. We repeatedly conveyed this message and offered athletes multiple opportunities to ask questions or seek clarity about the author's roles. It should be noted that university research ethical approval was gained and pseudonyms are used to maintain the athletes' anonymity. The findings emerging from the interviews are discussed next.

\section{Deaflympians Experiences of Sport}

A number of findings emerged from the four interviews concerning the various ways in which these D/deaf athletes have been enabled and challenged to engage in sport. These themes include: 'sampling years and sports participation'; 'discovering D/deaf sport'; 'the status and value of D/deaf sport'; and 'socially constructing 'hearing loss', Whilst each of 
these themes is discussed separately it is worth noting that they are interrelated and contribute to the athletes' sporting sense of self.

\title{
Sampling Years and Sports Participation
}

Three of the athletes indicated that their early involvement in sport included experiencing a range of different sporting activities, what Côté and Hay (2002) describe as the sampling stage. During this stage the athletes recognized how their family and physical education teachers were significant catalysts enabling their participation. Here Rav talks about the sports he was exposed to because other family members played them.

\begin{abstract}
All my family are into sports, they have won medals in tennis, squash, badminton, table tennis ..... I continued playing those sports, badminton, tennis, squash, locally and eventually regionally, then national. (Rav)
\end{abstract}

It is widely recognized that the family, particularly parents can be an important context in which sports participation is introduced, developed and maintained for young people (Kay, 2004; Wheeler and Green, 2014). Indeed, other athletes highlighted how their parents enabled their interest in sport to be maintained by taking them to training and events and generally showing an interest in the sports they were playing. Family was a positive and support conduit for sports participation for all four athletes in this study.

Karen and Sarah also identified school sport, and the support of physical education teachers, as being significant to their sampling years. 
I was getting into my running and the PE teachers were supportive and encouraging. They got me doing different things like hurdles and sprints, $100 \mathrm{~m}$, and it was the $800 \mathrm{~m}$ that I started doing for the school. Out of all my teachers I found the PE teachers to be most encouraging. (Sarah)

Sarah not only felt like she was exposed to different kinds of athletic activities but also that her physical education teachers positively supported her involvement in this sport. Whilst it is widely recognized that physical education can be a less than positive experience for many young people, for Sarah this was not the case (Kirk, 2010). However, David's experiences of physical education were less favourable and he recalls receiving little attention or support.

I was just expected to get on with it (PE), it was too much of a hard core thing for students with a disability ..... I hated high school so much I blanked it out. (David)

Initial experiences of sport through physical education can influence a young person's outlook towards sport in later life. In the case of David it is interesting to note that he continued to retain an interest in sport in spite of his negative experiences in physical education. It is also notable that within physical education, David identified himself as having a disability, something the other athletes did not acknowledge within this setting. The sampling stage remains important for all the athletes in terms of experiencing different sports. However, participating in D/deaf sport was something that did not feature at this time for the athletes. Next, consideration is given to the athletes and their discovering of D/deaf sport.

\section{Discovering D/deaf Sport}


Another key finding emerging from the interviews concerned the different ways in which both D/deaf and hearing sporting opportunities were experienced as a means of supporting participation. For all four athletes, their initial socialisation into sport in the sampling years had been within hearing spaces. In many respects this is not surprising given that all four respondents had attended mainstream schools and had no family members who were D/deaf. They all recalled that they were not made aware of D/deaf sport during these sampling years. However, as the athletes progressed from sampling through to specialising and investment they began to become aware of, and draw upon, opportunities in both hearing and D/deaf sport. How the athletes gained awareness of D/deaf sport differed but it was generally because of an incidental encounter. For example, Rav found out about the Deaflympics through a newspaper article and this was the first time he was made aware of separate competitions for $\mathrm{D} /$ deaf people.

I saw an article about the Deaflympics, I showed my dad and told him I wanted to go .... I thought I'm deaf so that would suit me .... I'd always played in the mainstream hearing competitions, so we didn't know how to get into the Deaflympics. (Rav)

Similarly, whilst competing in a hearing competition, Sarah come across a group of D/deaf athletes participating in a D/deaf athletics event.

I ran against other school children, there was no D/deaf group or athletes getting together, it was just everyone against everyone. There was no separate pathway and I have never seen it before in my life until I found out about the Deaflympics only three years ago, and only now I am still not aware of any D/deaf training groups that train together. (Sarah) 
Like Rav, this encounter exposed Sarah to D/deaf sport and the possibilities of an alternative sporting pathway. Whilst all of the athletes participate in D/deaf sport it is important to note that this is not the only pathway they continue to pursue sport through. Indeed, each of the four athletes crosscut differing types of provision similar to that found with non-disabled and disabled athletes (Fitzgerald, 2013). For example, Sarah participates in D/deaf elite sporting competitions and also engages at a high level in hearing events. She trains with a hearing coach and other hearing athletes. In crosscutting the hearing and D/deaf sport settings, these athletes demonstrate how they do not wish to be positioned in sport solely through their D/deaf or hearing identity and instead use the opportunities available to them to support their desire to participate in sport. By experiencing D/deaf and hearing sports the athletes were acutely aware of the differing values placed on Deaf/deaf and hearing sport and this issue is discussed next.

\section{The Status and Value of D/deaf Sport}

All four athletes were aware of the ways in which D/deaf sport was valued differently in relation to hearing sport. This valuing often positioned D/deaf sport as lesser than hearing sport in relation to funding, media coverage, use of facilities and coaches' attitudes. For example, Karen notes how limited funding is available for D/deaf athletes to compete in elite events like the Deaflympics. In her case, spending her own savings and securing a bank loan ensured she was financially able to compete internationally.

The fact that we have to fund ourselves for everything. I mean, I have $£ 17,000$ in my savings and it's gone on three competitions. I have bank loaned another one, I mean, you're living the dream, competing for your country, yet I don't feel I am 
competing for my country 'cause I paid for my vest. You see everyone from the London Olympics and all that, they've been given their vest, it's like a cap. You've won your cap, I’ve bought my cap because I haven't been awarded it. (Karen)

Karen felt she was 'living the dream', but she was also frustrated about the financial commitment she had made to achieve this. As well as issues relating to funding, Sarah was keen to highlight how the lack of publicity, media coverage and overall support had contributed to the lower status of the Deaflympics in relation to other elite events. Sarah acknowledges the temporary benefits that can be gained during the Deaflympics through the media but also believes this is relatively short lived.

Hell of a lot more publicity, funding and support ..... Better to have a lot more awareness out of the UK and well, I don't know ..... worldwide, because it feels like the rest of the world is here (Deaflympics), but I think back home, more financial support and media ..... I think four years is a long time to wait until the next Deaflympics .....I am just worried it will go quiet now. (Sarah)

The Paralympics have courted increasing media attention in recent years, yet the same cannot be said of Deaflympians who have continued to receive very little media attention (Foster, 2013; Clark and Mesch, 2018). As Sarah attests, the interim period between the four year cycle of the Deaflympics is the time where more sustained media support is needed. Similarly, David has made concerted efforts to secure sponsorship but has not been successful. He commented, 'I sent numerous emails to try and get sponsorship but it feels like the Deaflympics is invisible' (David). Like Sarah, David points to the lack of awareness of the Deaflympics when compared to an event like the Olympics. 
Another concern expressed by the athletes about the status of D/deaf sport relates to the lack of access to facilities to train or compete. There was a concern that facility providers and governing bodies of sport were less receptive to supporting D/deaf clubs to access facilities. For example, David noted a lack of access specifically in relation to cycling velodromes for D/deaf cycling clubs and during the Deaflympics.

Some sports like cycling, well, they don't have a velodrome so can't use it for track races, so have used an open road ..... There is a velodrome in Sofia but it wasn't even used [for the Deaflympics] even though it was available. (David)

For one of the athletes, Karen, her coach's negative response to her interest in getting involved in $\mathrm{D} /$ deaf sport was telling in relation to $\mathrm{D} / \mathrm{deaf}$ sport being valued less than hearing sport.

In 2007 she (friend) went to the Europeans and she said I could have won it so you should go. This was the problem I had ..... I was throwing massive for the age I was and I said to my coach at the time 'Look, how do you fancy me having a go at this D/deaf sport?' 'No', that was his response, because if I got channelled into that I wouldn't go anywhere else. Six months later I left him. (Karen)

Karen went on to successfully compete in D/deaf sport but feels her coach's negativity towards this pathway was damaging to D/deaf sport generally and those wanting to compete within this pathway. 
The valuing of $\mathrm{D} / \mathrm{deaf}$ sport as lesser to hearing sport in relation to funding, media coverage, facilities and coaches' attitudes reflects a location described by DePauw (1997) as the 'visibility of disability' in sport. Here DePauw is focusing on the location of disabled participants within sport rather than the extent to which their disability is visible or not. In this way, we could say the 'visibility of $\mathrm{D} /$ deafness' in sport. That is, $\mathrm{D} /$ deaf people are made visible (by having access and opportunities to sport). However, as the accounts from athletes above illustrate, their position in D/deaf sport is valued less than hearing people because they do not receive comparable credit, recognition or resources.

\section{Socially Constructing 'Hearing Loss'}

All four athletes experienced what Bauman and Murray (2009) describe as 'hearing loss', that is, disadvantage emerging from being $\mathrm{D} /$ deaf. The athletes reflected mainly on 'hearing loss' in relation to communication challenges and these accounts are evident across different settings and times in the athletes' lives. For example, during Côté's and Hay's (2002) sampling years Karen's recollections of schooling are dominated by the ways in which social and cultural practices within the school were organized around a hearing world. This influenced Karen's experiences of schooling and she talked about feeling excluded rather than included in lessons.

At primary school they didn't really help me out at all. We had a sports hall that was quite echoey. When we went outside ..... there was lots of noise outside, so it was just hard .....I was always sat at the front of the class which I did not like, because nobody wants to sit at the front when you are a teenager, sit there looking at the teacher, like a geek. (Karen) 
Although a solution had been found to enable Karen to better communicate with the teacher (to sit at the front of the class), this was also considered by Karen to have other costs - being geeky - that she believed impacted on her friendships with others in the class. David also reflected on his school experiences and the physical segregation he was subject to which distanced him from his classmates.

I would be taken away and told to do any homework that I had. Or do something else. But in a way that was detrimental because it pushed me away from all the other kids my age. Where has David gone? Why has he gone away? So detrimental. (David)

As David describes, this experience of segregation sometimes made him feel marginalized from his class and he was also aware that his classmates noticed and questioned this particular arrangement. Both Karen and David were conscious of the ways school practices marked them out as different and they believed this negatively impacted on their school experiences including in physical education classes. For Karen and David, these accounts of their hearing loss illustrate how they were, in Valentine's terms, 'out' of place in a school setting.

As well as school experiences, 'hearing loss' was also experienced in community sport. For some of the athletes, including Rav, this limited the social benefits accrued when participating in hearing sport. In particular, Rav noted that when competing in hearing competitions he tends to focus solely on his sporting performance because he feels excluded and 'out' of place from the wider dimensions of the sport that are premised upon a hearing world. 
In hearing competitions I get left out, I can focus on the game but don't get involved with communication. I am just there for the sport. I don't get any of the social, I have to rely on writing things down. (Rav)

Rav was frustrated with feeling left out and felt this limited his enjoyment of sport beyond active participation. Rav was also aware of how some sports were not conducive to D/deaf people playing. For example, he noted how the physical spaces of the squash courts offered further challenges during hearing competitions.

.... the squash courts were all walled rather than glass so for each point I had to keep turning around to hear the score. The hearing players could obviously hear the commentary so it was a pain to keep having to turn around. (Rav)

The other athletes also highlighted how assumptions made by hearing people within different sports impacted on their ability to communicate with teammates, understand officials and be supported by coaches. To some extent the experiences of Rav and the other athletes illustrate how the organisation of sport and those participating, such as hearing people, are unwilling to make adaptations in order to more fully involve D/deaf people (Rankin, 2012). Indeed, for all the athletes there was a consensus that D/deaf sport enabled more inclusive participation and a sense of community (Atherton, 2009b). Within this setting, Valentine's (2007) idea of being 'in', rather than 'out', of place is evident in their accounts. For example, here Rav emphasizes how this feeling of social and cultural acceptance is deeply rooted in his Deaf identity. 
Deaf sport I really feel that camaraderie, because you can really communicate with everyone. So Deaf sport is definitely in my blood. (Rav)

Within D/deaf sport an athlete's D/deaf identity is seen as a positive and in this way reflects Bauman and Murray’s (2009) 'deaf gain'. In this way, being D/deaf brought something positive to their experiences of sport rather than being considered as a disadvantage.

\section{Concluding Remarks}

Generally, we should take heed from the data available that illustrates that D/deaf youth and adults participate less in sport than hearing people (Rankin, 2012; Sport England, 2016). These differences in participation demonstrate that sport is not serving the D/deaf population well. This small-scale study builds on this participation data by offering some initial insights about the experiences of D/deaf people as they negotiate their participating in sport. For the $\mathrm{D} /$ deaf athletes in this study we recognize they are active participants in sport and reflections from those who do not participate may also be beneficial. That said, this study sheds light on what the possibilities and challenges are for those who do actively participate. In concluding we would like to make four observations.

First, like many young people, family and school were significant sites influencing participation in sport. During the D/deaf athletes sampling stage as youth, they were all directed to mainstream sporting opportunities. Whilst this is not a bad thing, it is limiting in that these athletes were not made aware of the wider possibilities they could have in terms of engaging in $\mathrm{D} / \mathrm{deaf}$ sport. The challenge remains to develop mechanisms that more effectively promote $\mathrm{D} / \mathrm{deaf}$ sport opportunities. It is important that practitioners such as coaches and physical education teachers better understand and advise young D/deaf people in order that 
the broad range of options available to them is clearly articulated and encompasses the possibilities of simultaneously crosscutting hearing and D/deaf sport.

Second, it is clear from this research that all four athletes enjoy participating in D/deaf sport and being part of a D/deaf sporting community. The athletes also seemed to gain an immense sense of achievement from these sporting endeavors. Interestingly, this was often tempered because they were aware of the ways in which D/deaf sport is valued less than hearing sport. Like disability sport, it would seem that $\mathrm{D} /$ deaf sport is seen as inferior to hearing sport and the athletes highlighted how they perceived this impacted on funding, media exposure and athlete recognition. The challenge remains to (re)position D/deaf people and D/deaf sport in ways that do not focus on deafness equating to inferiority.

Third, and related to the previous point, the athletes in this study seem to be more comfortable engaging in $\mathrm{D} /$ deaf sport. In part this was because deafness within $\mathrm{D} / \mathrm{deaf}$ sport is constituted in positive terms through deaf gain. This contrasts with their accounts of participating in hearing sport where deafness was often constructed in negative terms and associated with hearing loss. We believe the representation of D/deaf people through deaf gain should be more prominent in how physical education teachers, coaches, sport policy makers and other participants conceive of D/deaf people rather than taking a more traditional deficit approach based on hearing loss. Of course, this kind of change in mindset will not be easy to initiate but we would advocate for this to begin with students in higher education enrolled on sports related programmes. By developing our future practitioners in this way attitudes and perceptions may gradually shift in a way that promotes the merits of deaf gain in sport. 
Finally, in developing this paper we have become aware of the limited research within sport that focuses on D/deaf people and their experiences of sport as participants, coaches and sport managers. We believe this is a missed opportunity and one that is not enabling society to better understand factors contributing to D/deaf people's involvement and progression in sport. Relatedly, there is a wider base of scholarship underpinned by D/deaf studies that sport is currently not engaging with which would help to extend our knowledge and understanding about $\mathrm{D} /$ deaf people in sport. Both these areas of omission in sport reinforce a limiting rather than inclusive outlook to the participants and research conducted in sport.

\section{References}

Ammons, D. and Eickman, J. 2011. "Deaflympics and the Paralympics: eradicating misconceptions.” Sport in Society 14 (9): 1149-1164.

Atherton, M. 2009a. "Choosing to be deaf: issues of identity in the British deaf community." In Historical perspectives on social identities, edited by A. Brown, 129-136. Cambridge Scholars Press: Newcastle.

Atherton, M. 2009b. “A feeling as much as a place: leisure, deaf clubs and the British deaf community." Leisure Studies 28 (4): 443-454.

Atherton, M. 2012. Deafness, community and culture in Britain: leisure and cohesion, 19451995. Manchester University Press: Manchester. 
Bahan, B. I. 2008. "Upon the formation of a visual variety of the human race.” In Open Your Eyes: Deaf Studies Talking, edited by H.-D. Bauman, 83-99. Minneapolis: University of Minneapolis Press.

Bailey, R. and Morley, D. 2006. "Towards a model of talent development in physical education.” Sport Education and Society 11 (??): 211-230.

Barnes, C., Mercer, G. and Shakespeare, T. 1999. Exploring disability a sociological introduction. Cambridge: Polity Press.

Bauman, H. D, and Murray, J. J. 2010. 'Deaf Studies in the 21st Century: 'Deaf-gain' and the Future of Human Diversity.” In The Oxford Handbook of Deaf Studies, Language, and Education, edited by M. Marshark and P. E. Spencer, 210-225. New York: Oxford University Press.

Beacom, A., French, L. and Kendall, S. 2016. "Reframing impairment? Continuity and change in media representations of disability through the Paralympic Games.” International Journal of Sport Communication 9 (1): 42-62.

Braye, S., Dixon, K. and Gibbons, T. 2013. “A mockery of equality: an exploratory investigation into disabled activists' views of the Paralympic Games" Disability and Society 28 (7): 984-996.

Clark, B. and Mesch, J. 2018. “A global perspective on disparity of gender and disability for deaf female athletes" Sport in Society 21 (1): 64-75. 
Côté, J. and Hay, J. 2002. “Children's Involvement in Sport: A Developmental Perspective.” In Psychological Foundations of Sport, edited by J. M. Silva and D. E. Stevens, 484-502. London: Allyn and Bacon.

Côté, J, Baker, J. and Abernethy, B. 2007. "Practice to play in the development of sport expertise.” In Handbook of Sport Psychology, edited by R. Eklund and G. Tenenbaum, 184202. Hoboken, NJ: Wiley.

Côté, J. and Fraser-Thomas, J. 2007. "Youth Involvement in Sport.” In Sport Psychology : A Canadian Perspective, edited by P. R. E. Crocker, 266-294. Toronto, Pearson/Prentice Hall.

DePauw K. P. 1997. “The (In)Visability of DisAbility: cultural contexts and 'sporting bodies." Quest 49 (4): 416-430.

Department for Work and Pensions 2014. Paralympic data from the ONS Opinions and Lifestyle Survey. London: Department for Work and Pensions.

Dirksen, H., Bauman, L. and Murray, J. J., ed. 2014. Deaf Gain: Raising the stakes for human diversity. University of Minneapolis Press MUSE Project: Minneapolis.

Fitzgerald, H. 2013. “Disability and Sport Development.” In Sports Development: Policy, Process and Practice, edited by K. Hylton, 252-271. London: Routledge. 
Fitzgerald, H. and Long, J. 2017. "Integration or Special Provision? Positioning disabled people in sport and leisure.” In Sport, Leisure and Social Justice, edited by in J. Long, B. Watson and T. Fletcher, 126-138. London: Routledge.

Foster, R. 2013. "Is there an Olympic Legacy for Deaf Athletes?” Physical Education Matters 8 (2): 16-18.

Gagne', F. 1993. “Constructs and models pertaining to exceptional human abilities.” In International Handbook of Research and Development of Giftedness and Talent, edited by K.A. Heller, F.J. Monks, and A.H. Passow. Oxford: Pergamon Press.

Goggin, G. and Hutchins, B. 2017. "Media and the Paralympics: Progress, visibility and paradox.” In Managing the Paralympics, edited by S. Darcy, S. Frawley and D. Adair, 217239. London: Palgrave Macmillan.

Goodley, D. (2017) Disability Studies: An Interdisciplinary Introduction. London: Sage Publications.

Harrison, S.R. 2014. Same Spirit - Different Team: The Politicisation of the Deaflympics. Leicester: Action Deafness Books.

Jobling, I., Jobling, A. and Fitzgerald, H. 2008. "The Inclusion and Exclusion of Athletes with an Intellectual Disability.” In Benchmark Games: The Sydney 2000 Paralympic Games, edited by R. Cashman and S. Darcy, 201-216. Petersham: Australian Centre for Olympic Studies/Walla Walla Press. 
Kirk, D. 2010. Physical Education Futures. London: Routledge.

Kay, T. 2004. "The family factor in sport: A review of family factors affecting sports participation." In Driving up participation: The challenges for sport academic review papers commissioned by Sport England as contextual analysis to inform the preparation of the framework for sport in England. London: Sport England.

Kiuppis, F. 2016. "Inclusion in sport: disability and participation" Sport in Society 21 (1): 421, DOI: $10.1080 / 17430437.2016 .1225882$

Kusters, A., De Meulder, M. and O’Brein, D. (Eds.) (2017) Perspectives on deafness. Innovations in Deaf Studies. Oxford: Oxford University Press.

Ladd, P. and Lane, H. 2013. "Deaf ethnicity, Deafhood, and their relationship" Sign Language Studies 13 (4): 565-579.

Leigh, I.W. and Andrews, J.F. (2017) Deaf People and Society. Psychological, Sociological and Educational Perspectives. London: Routledge.

Macbeth J. L. 2010. "Reflecting on disability research in sport and leisure settings" Leisure Studies 29 (4): 477-485.

National Disability Sport Organisations 2015. Active beyond education. London: National Disability Sport Organisations/English Federation of Disability Sport. 
National Deaf Children's Society 2013. Information about deafness and hearing loss. London: Department for Education.

Peers D. 2018. "Sport and Social Movements by and for Disability and Deaf Communities: Important Differences in Self-Determination, Politicisation, and Activism." In The Palgrave Handbook of Paralympic Studies, edited by I. Brittain and A. Beacom, 71-97. London: Palgrave Macmillan.

Rankin, M. A. 2012. Exploring why disabled people and deaf people do and don't participate in sport. Loughborough: English Federation of Disability Sport.

Lloyd, R.S., Oliver, J.L., Faigenbaum, A.D., Howard, R., De Ste Croix, M.B.A., Williams, C.A., Best, T.M., Alvar, B.A., Micheli, L.J., Thomas, P., Hatfield, D.L., Cronin, J.B. and Myer, G.D. 2015. “Long-term athletic development - Part 1: A Pathway for all Youth" Journal of Strength and Conditioning Research 29 (5): 1439-1450.

SCOPE 2016. "Do the Paralypmics have the power to improve attitudes to disability?" Available from: <https://blog.scope.org.uk/2016/09/05/do-the-paralympics-have-the-powerto-improve-attitudes-to-disability/> [Accessed $4^{\text {th }}$ August 2017].

Solvang, P. K. and Haualand, H. 2014. "Accessibility and diversity: Deaf space in action" Scandinavian Journal of Disability Research 16 (1): 1-13.

Sport England 2001. Young people with a disability and sport. London: Sport England. 
Sport England 2017. Active people survey. London: Sport England.

Valentine, G. 2007. "Theorising and Researching Intersectionality: A Challenge for Feminist Geography" The Professional Geographer 59 (1): 10-21.

Valentine, G. and Skelton, T. 2003. "Living on the edge: The marginalisation and resistance of D/deaf Youth” Environment and Planning A: Economy and Space 35 (2): 301-321.

West, C. and Fenstermaker, S. 1995. "Doing Difference" Gender and Society 9 (1): 8-37.

Wheeler, S. and Green, K. 2014. 'Parenting in relation to children's sports participation: generational changes and implications" Leisure Studies 33 (3): 267-284.

i Of course, our understanding and articulation of 'D/deaf people' may not inline with some readers of this journal. In briefly stating our position we are merely attempting to be transparent about the reasons underpinning our thinking on this issue. We also acknowledge that there are other important associated terms that readers may want to familiarise themselves with including disability, hearing and BSL (see for example: Goodley, 2017; Kusters, De Meulder and O'Brien, 2017; Leigh and Andrews, 2017). 